\title{
The Influence of Open Source Software on Creativity, Communication and Students' Social Life
}

\author{
Dejan Viduka \\ University Business Academy - Novi Sad, \\ Faculty of Applied Management, \\ Economics and Finance \\ Belgrade, Serbia \\ dejan@viduka.info \\ Biljana Viduka \\ University Business Academy - Novi Sad, \\ Faculty of Applied Management, \\ Economics and Finance \\ Belgrade, Serbia \\ biljana@viduka.info
}

\section{Davor Vrandečić}

J. J. Strossmayer University of Osijek,

Faculty of Electrical Engineering, Computer Science and Information Technology Osijek,

Kneza Trpimira 2b, Osijek, Croatia

davor.vrandecic@ferit.hr

\begin{abstract}
Today's global, knowledge-based society and economy need creative thinkers in all fields: engineering, medicine, arts, entrepreneurship and education. Educational institutions are tasked with finding new ways of encouraging students to become creative both as individuals and groups. Still, motivation and creativity are only a few of the primary educational goals. They are ambiguous by nature, theoretical, and hard to implement in the real world. Nevertheless, it is a common belief that creativity is an important trait that students should possess in order to face the quickly evolving world. The purpose of this study is to examine the related published works on games, software, imagination, education and creativity. We seek to gather useful information that would both draw attention to this problem and how Open-Source Software (OSS), as a model, can drive students' creativity.
\end{abstract}

Keywords - creativity, education, open source software, digital gap, innovation

\section{INTRODUCTION}

Information and communication technology is a force that has changed many aspects of our lives. In the beginning of the twenty-first century informational technology became an inevitable element in education. The vast possibilities that such technology provides are insufficiently leveraged in many developing countries. This situation is due not only to deficient school equipment but also to poor teachers' training for the usage of such equipment. This situation has been changing over the past few years mostly due to the increasing number of schools that are equipped with IT infrastructure. At the same time, the internet connection in developing countries is improving as well [1].
Generally speaking, our culture, along with our lives at home, at work, and in school are becoming extremely integrated with technology [2]. Unlike the traditional teacher-based teaching that rests on on one-way communication, the use of IT and OSS as teaching tools is possible in all stages of primary, secondary and college education. Even though there are disagreements in terms of how much computers actually generate creativity, there is a general consensus that they can transform and inspire human creativity [3]. The contribution of such means to the learning process consists of encouraging students in the classroom as well as during independent studies to be as efficient as possible. Such processes include solving problems, divergent thinking, different combinations, metaphorical thinking, and analogy [4]. 
According to the futurist, Alvin Toffler, the illiterate people of the twenty-first century "will not be the ones who do not know how to read, but those who are incapable of learning"[5] The use of IT and OSS will trigger interest in children to recognize, research and solve the problem in question throughout the whole learning process. Many countries and schools mostly use commercial software that is very expensive and therefore inaccessible for many other schools. The high price is one of the major problems that prevents schools with poor financial means from integrating technology into their curriculum. Fortunately, there is an alternative software that can offer some assistance to schools. Alternative software refers to Open Source Software that is very useful in the field of mathematics, numerical analysis, data processing, graphics, text processing and other similar products. The use of OSS in computer science education is in expansion in the last several years. Open code software refers to all the software whose source code is available under the "Open Source" license [6]. Source code is accessible in some programming languages. Unlike commercial tools, OSS can be changed and rearranged according to one's personal needs. Technical training was introduced in formal programs which resulted in influencing the cultural and pedagogical paradigm in education [7].

Aside from the technical aspect, it is important to mention that the author of OSS may use his or her experience as a starting point for discussion on social aspects of software engineering such as ethics and licensing laws for software. Some of the research showed the existence of different learning styles that represent strategy or regular mental behavior that individuals habitually apply in the process of learning [8].

To have success with those changes in the field of science and technology we have to work on modernization in the field of education. Modern education is expected to shape students as flexible individuals who will easily accept current changes. Such needs imposed certain changes in the way how we organize classes. The organization of classes with the help from computers has certain advantages over the traditional organization. Some of them are the following:

(1) Teaching and learning process with the whole class can be simultaneously individualized. (2) Educational programs are of better quality. This guarantees better learning results, better approach and endless motivational possibilities. (3) Computer-based educational programs trigger more senses for learning. (4) Efficient learning is no longer explicitly linked to the educational institution, classroom, or a working day or hour. (5) Computers can simplify the grading process and lower the likelihood of a teacher making a mistake while grading a students work. (6) Computers in education can be used for a stream of different activities such as: efficient management of learning processes, governance of many administrative and personal projects, and many other types of work related to imminent organization and realization of broader work in education.
It is our obligation to provide students with opportunities to practice and raise their natural creative abilities. In order to make education more efficient, we have to create proper learning environments in our classrooms [9]. If teachers are reluctant to accept digital technology, it may open a gap between educators who are slow to go along with technology and the world that assimilated technology quickly [10]. One of the main duties of every educational reform is not only to equip schools with modern computer devices and other high-tech equipment but also to provide the basic tutoring for their application.

\section{OPEN SOURCE SOFTWARE}

Open Source programs are seen by average computer users as something that is free of charge but also as something that is not good enough and that lacks the quality for commercial use. OSS or free software is often defined as a free software. The basic philosophy of OSS is extremely simple. When software programmers are allowed to work freely on their source code, it is inevitable that it will improve because collaboration helps with fixing mistakes. Collaboration also enables adjustment to different needs and hardware platforms [11]. OSS is becoming more popular by the day. OSS distinguishes itself from other programming solutions in the way how it is made and how much it costs. OSS licenses enable a lot of freedom for the distribution of software, although they do not necessarily return large profits for their authors. Such licenses facilitate free use as well as modifications for personal needs [12].

In the world of computer science, there are software programs that are free of charge, but only in the sense of free use [13]. Users are forbidden from distributing and improving such programs. In such cases there are no guarantees that those programs will be available for use in the future. They are usually used for marketing and promotional purposes. Contrary to this programs that are free of charge, but not free to change, OSS can always be adapted by the end user and is very often free of charge. The free use of OSS is reflected in the fact that the licenses guarantee their use, but the author maintains the selling rights as well as the rights to change the license. This implies that everything that has been licensed as a free software once, remains under the license regardless of modifications and regardless of who introduces those changes. Free software can be modified under clearly defined rules.

\subsection{OPEN SOURCE DEFINITION}

Open Source is a category of methods and technologies that is used in developing computer software that is accessible to broad communities without major limitations. In order to better develop the software, communication between developers and users takes place. The source code of the program in such cases is the final product of the Open Source process. Evolution of such communities creates additional products and 
services that often lead to developing independent projects. Programmers are not the only ones who participate in developing these projects. The majority of software users can contribute (through testing, asking questions, translations, directions, tracking of mistakes, promotion and support for the less experienced users) to a faster envelopment of projects [14].

\subsection{OPEN SOURCE COMMUNITY}

The main advantage of the open source software is its accessibility and possibility for modification and advancement. In fact, there are lot of studies that identify factors that can lead individuals to participate in OSS projects [15]. The prerogative of this concept is the possibility to attract free-lance programers to advance and further develop programs. Members of those communities regularly communicate with each other in order to exchange their knowledge and collaborate in the search for solutions to problems that may arise [16].

The development of the internet enabled users to communicate with each other and to work on such software. Previously, there was a communication problem caused by geographical and other limitations, which is why Open Source used to be more limited before widespread internet use. Today it is possible to write a program, publish it under one of the free licenses, and upload it to internet either for free use or in order to sell it. Today authors can simply search the internet looking for similar solutions to what they are programming. There are many free programs online that publish precisely what the author needs, but they also allow adjustments to individual needs [14].

There is a variety of completely functional operating systems, as well as many included apps, that are widely used and do not require the purchase of any commercial computer program.

The typical open source software author is a relatively young programmer. There are, of course, older users who, while applying their knowledge and effort, make a living with programming. In their spare time, as a hobby or as a matter of prestige, they may work on further development of an open source project. Such groups of developers, when compared to big software development companies that are stationed at a fixed place and led by their managers, have less chance of success and less chance of finding clients.

In spite of the common opinion that individuals cannot outsmart the software companies, OS is fighting its way through the mainstream software for massive use. The reasons for the success can be found in high quality technology that they use as well as in a very quick pace by which the OS spreads among users. All this enables the open code software to make a break through and fight the competition.

\section{OPEN SOURCE SOFTWARE INFLUENCE}

In the twenty-first century, creativity poses one of the essential projections of human existence, and it is very present in furthering education. Many institutions that deal with this field refer to creativity very often. Creativity is viewed differently in different disciplines. In education we call it "innovation", in business we call it "entrepreneurship" and in music it is called "performance" or "composition"[17]. Most researchers agree that creativity is a production of something that is original and worthy. "Something" can be a theory, a dance, a chemical product, a process, a dinner or anything else [18].

Since the beginning of this century, creativity has been perceived as a characteristic and a necessity of every human being. Through follow-up research and work with young people who are well disposed towards creativity, we are able to increase the development of creativity with adult individuals. It is precisely because of such needs in our modern society that we have to pay attention to all the possible ways of enabling the development of creativity with young people in the course of their education.

One of the reasons is the lack of knowledge and skills about creativity that should be taught in higher education [19]. Creativity is not represented in colleges and universities in an adequate way and it could be viewed as a consequence of their personal experience. It can be seen as an insight into the lack of creativity in college education. It can also be linked to critique that is characteristic for the younger generation [20].

Motivation and creativity are some of the primary educational goals. They are naturally unstable, hard to understand and are often speculated on [21]. Aside from savings and flexibility that are achieved by the usage of OSS, schools will be in the position to show their leadership in solving problems related to social and ethical issues. Creative individuals invent. They imagine different situations and things, solve problems in various fields, and make communication through innovative methods possible [22]. Creative thinking skills imply the search for innovation and difference. They imply independence, persistence and high aspirations and standards [23].

Globalization brings along the internationalization of knowledge and it exerts pressure on modern states and nations to be involved in those processes [24]. There are several reasons why the operational definition of creativity based on the product seems to be the most appropriate [25]. The scope and the nature of creativity of new products is key to managing innovation [26].

OSS helps to overcome the issue of digital gap because it removes the burden of expenses and limitations of software licenses for schools. It results in a more accessible IT in schools [14]. This way the schools would be able to create the ICT (Information - Communication and Technology) environment that would satisfy the needs of a larger number of students. In addition, 
there is a possibility to help the students and their families who do not have a new computer at home which would enable them to set up the new software. One example would be for schools to define which GNU/Linux distribution they use in their classes.

Facilitating access to the same software packages for all students would be very helpful, and it would not require additional financial means for classes. Since the software requirements for setting up this operating system are quite modest, it can be installed even on older computer models. Purchasing them is also much cheaper.

There is a number of social issues that schools encounter while introducing ICT One of the most important responsibilities of the schools is making sure that all students have equal access to it [27]. The integration of ICT in schools demands a special attention to its influence on digital distribution. Digital distribution refers to the gap between those who can use new information and communication tools efficiently and those who cannot. Research on the digital gap is often focused on socioeconomic factors and their influence on family income, level of education and equality. When education is in question, the focus is often on the approach to modern technologies that are available both at school and at home. Any kind of modern technology is expensive once it first appears on the market and only a limited number of users can afford it. As a result, students with modest means do not have the opportunity to have access to technology outside the school.

When students can read, distribute, and modify software, they can get included into a large community of programmers who constantly work on exchange of ideas and removal of programming mistakes. Such communities (Figure 1.) gather a great number of activists who foster various OSS projects via the internet regardless of where they live. Such a unique type of virtual community provides an ideal learning environment that teaches how to communicate, cooperate, and eventually learn from other members of the community. Constant improvement, production and efficient reception of new services, products or processes poses a huge industrial challenge [28]. OSS has become more accessible and more successful in the last decade mainly because of the growing number of users who exchange ideas and work on improving OSS software. Different types of online behavior are positively correlated [33].

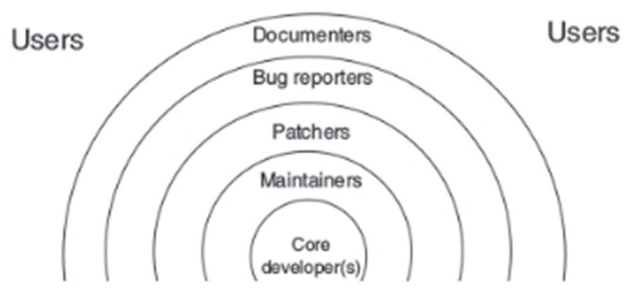

Fig. 1: Image of OSS organization and structure

This way students communicate with their peers with whom they share the same passion. This helps them to master their computer skills, their communication skills as well as their English skills (English being the language mainly used in communication) [29]. Creativity, and its essential role in the classroom, is often considered to be the answer to the background of quick social, technological, spiritual and ecological changes [30]. OSS is a resource for development of innovation and creativity of its users. When it comes to schools, it is a resource for furthering knowledge during the process of learning. Motives for involving with OSS can be defined in three categories:

- enjoyment based on inner motivation

- obligation towards the community

- outside motivation

\section{EXAMPLES OF OSS USAGE IN EDUCATION}

In most cases, teachers decide to teach their students with commercial software applications. The usage of OSS in computer education has expanded in the last several years. One of the exceptions is the subject called "programming" that is being researched in schools of higher education. The learning process basically comes down to learning how to program cell phone application for Android, being the operating system that dominates the world market.

It is estimated that Android takes up more than $80 \%$ of the cell phone market. In the same fashion the subject of internet technology or web programming in schools is taught in order to learn how to use of HTML, CSS, JavaScript and PHP programming languages, or some of the WCMS (Web Content Management System) solutions as for example Joomla, Wordpress or Drupal, which are also developed under the OS licenses.

There are other examples that can teach students how to use OSS and that can be an excellent choice depending on the needs of the user. OSS could be distributed in different ways for the needs of learning processes that take place in a classroom. Its anatomy, with an available source code, gives students a unique opportunity to freely experiment with the goal of achieving a better education. Much can be learned by using OSS that is based on practical examples as opposed to theoretical learning. That kind of learning has often been embraced by teachers who use books with their simple examples.

This system enables the users during their educational process to freely "peep below the hood" and see the complex systems in which they are written and how they are projected in practice on intricate software solutions. It is those examples that show very clearly that it is essential to introduce the OSS in higher education especially in schools that research software engineering and areas of study that would introduce students into OSS philosophy. By doing this their attention would be drawn to both advantages and disadvantages of the currently known software packages. This type of education enables students with greater opportunities for an independent choice of software that they 
would use in their studies and work. At the same time it shortens the time that each individual might need in order to discover the possibilities this concept offers.

\section{CONCLUSIONS}

Nowadays, developed countries use educational systems more and more as open and flexible modules that are incorporated into digital contents. Educational technology applies them efficiently. In developed countries, educational software is a part of the learning process starting with the primary education. A new model of teaching that students are more interested in has been created so that students are more motivated compared to the model that was used previously. Specific software development skills are being researched outside the university systems, in trade schools, interim courses or short courses [31].

The tools for such processes are easily available, mostly free of charge and they are also enriched by multimedia contents. They are also accessible through the web so that both teachers and students can adjust to new technologies by using interesting methods. Using such tools teaches students to present their papers and thesis as well as to play didactically elaborated games and solve assignments while using computers.

Following this course, the new electronic, multimedia based and interactive model of learning is being introduced. This model increases the students' motivation for and efficiency at learning the material. Educational software, with a help of technological devices (internet connection, connected computers, projectors and smart boards, etc.) contribute to better learning. Implemented learning software enables all the classical types of approaches like pair work, individual work and group work.

The methods of learning and presenting while using electrical boards (interactive boards, smart boards) put students in an active role in the process of learning and acquiring knowledge (projected pedagogy). The possibilities that these new media offer (like for example, internet, multimedia-learning, projected educational contents, experience) will enable the building of new teaching models whose effects will be measurable. While using the internet, students will acquire technical skills and enter the virtual world. (Each one of these models has its advantages and disadvantages, which is why we have to strive towards optimal use.)

Bulgaria is a good example where the use of OSS was approved by a legal act. As a result, it was introduced in education as well as in other areas. OSS can help to facilitate work, and it is good to know that OSS is good enough to be considered as an alternative to other expensive software. Microsoft Office packages where the user learns how to use the tools (text editing, spread sheets, contents presentation etc.) can be replaced by a LibreOffice package that is free of charge. This tells us that it is essential to learn how to use the tools and how to create a document and insert graphics, pictures, tables, etc. It would be good to implement the example of Bulgaria to other countries. Then, new standardized books would be published that would teach teachers. Eventually those materials would be used for teaching purposes. As a matter of fact, it is the teachers themselves who enable the maximum learning potential of their students. They are also a channel for releasing of those potentials in the classroom [32]. Aside from basic convenience it is necessary to thoroughly look into the advantages of OSS. Some of the advantages that students have while applying this concept influence the developing of creativity, communication and social skills.

\section{REFERENCES}

[1] D. Viduka, B. Viduka, "Term and Implementation of Electronic Education in Serbia", Proceedings of the $4^{\text {th }}$ International Conference on Technics and Informatics in Education, Čačak, Serbia, 1-3 June 2012, pp. 461-468. (in Serbian)

[2] T. Alexander, "TechKnowLogia", Proceedings of the International Conference on "Dissolving Boundaries: ICTs and Learning in the Information Age", Dublin, Ireland, 4-5 May, 1999.

[3] J. McCormack, M. D'Inverno, "Computers and Creativity: The Road Ahead", Computers and Creativity, Springer, Berlin, Heidelberg, 2012, pp. 421-424.

[4] T. Lewis, "Creativity in technology education: providing children with glimpses of their inventive potential", International Journal of Technology and Design Education, Vol. 19, 2009, pp. 255-268.

[5] V. L. Tinio, ICT in Education, Manila E-ASEAN Task Force, Kuala Lumpur, 2003.

[6] D. Viduka, "Possibilities of using Open Source software in modern business", Proceedings of the $12^{\text {th }}$ International Conference on E-commerce, Palić, Serbia, 2012.

[7] K. Kazerounian, S. Foley, "Barriers to creativity in engineering education: A study of instructors and students perceptions", Journal of Mechanical Design, Vol. 129, No. 7, 2007, pp. 761-768.

[8] V. Ružić., R. Nikolić, N. Žižović, “Electronic materials for blended learning", YU INFO Conference, 2010.

[9] R. M. Felder, "Creativity in Engineering Education", Chemical Engineering Education, Vol. 22, No. 3, 1988, pp. 120-125.

[10] J. Blac, K. Browning, "Creativity in Digital Art Education Teaching Practices", Art Education, Vol. 64, No. 5, 2015, pp. 19-34. 
[11] A. Bonaccorsi, C. Rossi, "Why Open Source software can succeed", Research Policy, Vol. 32, No. 7, 2003, pp. 1243-1258.

[12] C. A. Kenwood, "A Business Case Study of Open Source Software", Mitre Corporation, MP 01B0000048, 2001

[13] H. Singh, D. Seehan, "Open Source vs. Proprietary Solutions: Case Study of Windows and Linux, A Consumer Perspective", International Journal of Advanced Technology \& Engineering Research, Vol. 2, No. 4, 2012, pp. 28-37.

[14] D. Viduka, "Interoperability model of information system based on open source software in education", Singidunum University, Belgrade, Serbia, PhD Thesis, 2017. (in Serbian)

[15] W. Ke, P. Zhang, "The Effects of Extrinsic Motivations and Satisfaction in Open Source Software Development", Journal of the Association for Information Systems Vol. 11, No. 12, 2010, pp.784-808.

[16] Y. Ye, K. Kishida, "Toward an Understanding of the Motivation of Open Source Software Developers", Proceedings of the $25^{\text {th }}$ International Conference on Software Engineering, Portland Oregon, USA, 3-10 May 2003, pp. 419-429.

[17] D. C. C. K. Kowaltowski, G. Bianchi, V. Teixeira de Paiva, "Methods that may stimulate creativity and their use in architectural design education", International Journal of Technology and Design Education, Vol. 20, 2010, pp. 453-476.

[18] Lj. Arar, Ž. Racki, "The nature of creativity", Psychological topics, No. 12, 2003, pp. 3-22.

[19] A. K. Palaniappan, "Web-based Creativity Assessment System", International Journal of Information and Education Technology, Vol. 2, No. 3, 2012, pp. 255-258

[20] S. B. Maksić, V. Z. Spasenović, “Educational Science Students Implicit Theories of Creativity", Creativity Research Journal, Vol.30, No. 3, 2018, pp. 287-294.

[21] P. Chakalisa, D. Mapolelo, D. M. Totev, Ir. E. D. Totev, "Modern Methods for Stimulating Creativity in Education", Informatica, Vol. 30, 2006, pp. 421-425.

[22] A. Cocua, E. Pecheanua, I. Susnea, "Stimulating Creativity through Collaboration in an Innovation
Laboratory", Procedia - Social and Behavioral Sciences, Vol. 182, 2015, pp. 173-178.

[23] L. G. Richards, "Stimulating creativity: teaching engineers to be innovators", Proceedings of the $28^{\text {th }}$ Annual Frontiers in Education Conference. Moving from 'Teacher-Centered' to 'Learner-Centered' Education, Tempe, Arizona, USA, 4-7 November 1998, pp. 1034-1039.

[24] S. Maksic, "Encouraging creativity in school", Institute for Pedagogical Research, Belgrade, Serbia, ISBN 89-7447-068-8., 2007.

[25] T. M. Amabile, "The Social Psychology of Creativity: A Componential Conceptualization", Journal of Personality and Social Psychology, Vol. 45, No. 2, 1983, pp. 357-376.

[26] D. H. Cropley, J. C. Kaufman, A. J. Cropley, "Measuring Creativity for Innovation Management", Journal of Technology Management \& Innovation, Vol. 6, No. 3, 2011, pp. 3-30.

[27] D. Viduka, A. Basic, B. Viduka, V. Varadjanin, "Open Source software as Alliterative and Effective Learning Environments", Journal SYLWAN, Vol. 161, No. 6, 2017.

[28] L. A. Zampetakis, L. Tsironis, V. Moustakis, "Creativity development in engineering education: the case of mind mapping", Journal of Management Development, Vol. 26, No. 4, 2007, pp. 370-380.

[29] D. Viduka, A. Bašić, V. Kraguljac, "Social Engineering of Open Source Software", Serbian Journal of Engineering Management, Vol. 3, No. 1, 2018, pp. 56-60.

[30] A. Craft, "Creativity in Schools: Tensions and Dilemmas", Abingdon, Routledge, 2005.

[31] M. Shaw, "Software Engineering Education: a Roadmap", Proceedings of the Conference on The Future of Software Engineering, Limerick, Ireland, June 2000, pp. 371-380.

[32] K. C. Tsai, "Play, Imagination, and Creativity: A Brief Literature Review", Journal of Education and Learning; Vol. 1, No. 2, 2012, pp. 15-20.

[33] I. Boric Letica, "Some Correlates of Risky User Behavior and ICT Security Awareness of Secondary School Students", International Journal of Electrical and Computer Engineering Systems, Vol. 10, No. 2, 2019, pp. 85-89. 